\title{
EDITORIAL
}

\section{MED 25 AÑOS: EL NACIMIENTO DE UNA IDEA HECHA REALIDAD}

\author{
Diego A. Rodríguez MD, Jairo Zulliani MD, \\ Carlos Riveros MD, Ivan L. Cepeda MD, Jorge A. Espinosa MD \\ Egresados Facultad de Medicina. Universidad Militar Nueva Granada
}

Nos sentimos honrados y agradecidos de tener la oportunidad de contar la historia nunca antes contada sobre cómo surgió Med. Honrados por haber sido los estudiantes que fundaron la revista y agradecidos con todos aquellos que en estos 25 años han mantenido vivo ese sueño casi inalcanzable de tener un órgano de difusión científica de la Facultad de Medicina de la Universidad Militar Nueva Granada y el Hospital Militar Central. Gracias a 25 años de esfuerzos continuos, la esencia de Med sigue intacta, ser una revista médica propia, en busca de la excelencia, de todos y para todos.

\section{7 de mayo de 1991. El día ha llegado}

Son las 11 de la mañana. El lanzamiento oficial de Med es a las 5 de la tarde. Las directivas del la Universidad y del Hospital Militar están invitados. Hasta el ministro de salud está invitado. Todos sabemos exactamente qué hacer para estar listos, una vez cumplamos con nuestras responsabilidades del día como estudiantes de medicina. Entre rotaciones clínicas, turnos y exámenes, hemos trabajado durante siete meses para este día. No hemos dormido mucho en meses e incluso menos en los últimos días, pero estamos listos, bueno... casi listos. Solo falta un detalle. A seis horas del lanzamiento, aun no tenemos el primer ejemplar de Med en nuestras manos. La verdad, nadie la ha visto. La impresión de la revista tomó más tiempo de lo esperado. El encargado del taller de impresión está haciendo su mejor esfuerzo para secar las impresiones manualmente y hará todo lo posible por entregarnos unos pocos ejemplares para la ceremonia de lanzamiento. Incluso si se alcanzan a secar unos ejemplares, aun no sabemos cómo van a llegar del taller hasta el auditorio del Hospital Militar...Un solo pensamiento llenaba nuestras mentes: "Fallar, no es una opción!"

Agosto de 1990. Nace una idea

Estamos terminando el 5 año de medicina y entre pacientes, rotaciones y exámenes tratamos de prepararnos para el futuro de la mejor manera. Es en ese momento que notamos que algo no estaba bien. En los años anteriores, cada uno de nosotros se había esforzado por producir una cantidad considerable de investigaciones y trabajos clínicos de muy buena calidad; sin embargo, lo más probable era que se quedaran archivados en los anaqueles de los servicios del hospital o en las oficinas de nuestros profesores.

Como ejemplos de ello se contaban: el trabajo en el que basados en entrevistas a pacientes con cáncer, encuestas a médicos tratantes y una revisión minuciosa de la literatura disponible en el momento, evaluamos los aspectos más importantes de la relación médico-paciente oncológico en el Hospital Militar Central de Bogotá y propusimos pautas y estrategias para hacerla aun mejor.

O la propuesta que presentamos sobre la necesidad de incluir un curso de educación sexual en nuestro currículo para estar mejor preparados para educar a la comunidad en este aspecto.

Para cinco de nosotros, es allí donde nació la idea de crear una revista científica donde esos trabajos pudieran ser publicados y consultados por el mayor número de profesionales de la salud posible, y que de esta manera nuestros esfuerzos trascendieran las paredes de las aulas de nuestra universidad. 
Octubre del 1990. Nace una revista

Durante la primera reunión en la biblioteca, comenzamos a poner los pilares de este nuevo intento por hacer una revista. Nos permitimos pensar en grande. Definimos los objetivos, revisamos todos los ejemplos disponibles para asegúranos de hacer la mejor revista médica estudiantil del país en el momento, nos organizamos de la manera más estratégica que pudimos concebir, planteamos un cronograma y a nuestros planes le siguió la acción.

A diferencia de "Suturas", nuestra publicación sería solo de artículos científicos. Para poder avanzar en múltiples frentes al mismo tiempo, conformamos cinco divisiones de la siguiente manera: Revisión de artículos (responsable del contenido), Diseño y Diagramación (responsable de la forma), Financiera y Jurídica (encargada de los complejos asuntos financieros y legales), Promoción y Motivación (encargada de estimular la producción de artículos) y Relaciones Públicas (responsable de establecer alianzas estratégicas con el Hospital, La Asociación de Exalumnos, la Asociación de Amigos de la EMIM y encontrar financiación).

Necesitábamos asegurar su continuidad, sobretodo después de que todos nosotros ya nos hubiéramos graduado. Para lograrlo, cada uno de nosotros lideraría una de las cinco divisiones y conseguiría un equipo de estudiantes de todos los años, de primero a quinto, que de manera colaborativa y con mucho sentido de pertenencia, trabajara en lograr los objetivos de cada división y así pasar de generación en generación la responsabilidad de mantener viva la idea en el tiempo. ¿Nuestro lema? "¡El fracaso no nos sobrecogerá nunca, si nuestra determinación por alcanzar el éxito es suficientemente poderosa!"

Noviembre de 1990. Necesitábamos un nombre

No podíamos seguir llamándola "la revista". Tampoco queríamos decidir nosotros un nombre e imponerlo. Vimos la oportunidad para promocionar la revista y aumentar el sentido de pertenencia en el que tanto creíamos. Así que decidimos realizar un concurso en el que todos podían participar. "Med", fue el nombre elegido; las tres primeras letras relacionadas con la ciencia médica en todas las lenguas romances. Un nombre ágil, sencillo y corto, de fácil memorización y de gran impacto visual. Esto garantizaría su permanencia en la mente de todos aquellos que escucharan su nombre. Gracias Diana Barbudo por bautizar al Med!

Diciembre de 1990. De cerca y de lejos

Por esta época estábamos preparándonos para empezar el internado, dos de nosotros en otras partes del país. Esas dos divisiones necesitaban un representante adicional en Bogotá. Fue así como se conformó el grupo final de líderes, que sin importar donde estuvieran, guiarían el desarrollo de Med: Iván Cepeda, Diego Rodríguez, Jairo Zuliani, Fabio Pedraza, Luis Fernando Echeverri, Carlos Riveros y Jorge Espinosa, nuestro primer director.

Los valiosos consejos de nuestros asesores ayudaron a ponerle dirección a las velas de Med, guiándola desde un agitado mar abierto al puerto seguro donde queríamos ir. Fueron fundamentales el Dr. Diego Andrés Rosselli, la Dra. Margarita Guzmán, la Dra. Yuri Takeuchi, el Dr. Pedro Ibarra, el Dr. Ernesto Laverde, la Dra. Erika Cuervo, el Dr. Humberto Ballesteros, el Dr. Julio Alberto Nieto, el Dr. Alfredo León y el Dr. Jorge Solano. El apoyo de las directivas de la Universidad y de la Facultad, la Asociación de exalumnos (AEXEMIM) y la Asociación de Amigos de la Escuela Militar de Medicina y Ciencias de la Salud (ASAEM) fueron instrumentales para hacerla realidad. 
Enero de 1991. Entre materias, exámenes y pacientes

Más de 35 estudiantes de todos los años se movían por la facultad y por los diferentes hospitales afiliados aprendiendo medicina como sus compañeros, pero además, consiguiendo artículos, revisando textos, diagramando páginas, consiguiendo fondos, y convenciendo a los incrédulos de que una revista de alta calidad científica se estaba forjando. Es decir, aprendiendo a construir una revista médica. La División de Revisión de Artículos aprendía a seguir de manera estricta un libro de corrección de estilo de textos médicos, La División de Diseño y Diagramación aprendía aceleradamente a manejar un programa para diagramar publicaciones en computador, la División de Promoción y Motivación conseguía los primeros artículos, mientras que La División de Relaciones Públicas conseguía los primeros fondos y la División Financiera y Jurídica aprendía qué hacer con ellos.

Marzo de 1991. Objetivos guiados por principios

Para este momento ya teníamos claro cuáles serían los principales objetivos de Med: Fomentar el espíritu investigativo de los estudiantes de la facultad, difundir sus trabajos de investigación y revisión, servir de apoyo académico en las clases y lo más importante, conformar una unidad de conceptos y actitudes, tanto éticos como profesionales, para compartirlos y ayudar a la causa de mejorar nuestra salud dejando un registro escrito de la historia y contribuciones de la Facultad de Medicina de la Universidad Militar Nueva Granada y el Hospital Militar Central.

\section{Abril 1991 Med consigue un lugar en la Facultad}

Gracias a la Asociación de Exalumnos y la de amigos de la Escuela, conseguimos una oficina en el tercer piso de la biblioteca de la facultad y fue allí, en la pared de esa oficina, donde por primera vez se imprimió el logo de la revista. Grande, ágil, rojo, resumía para todos los que lo veían una voluntad de trabajo a toda prueba.

Para este momento las divisiones de trabajo andaban a toda máquina hacia la recta final. Motivación y Promoción convencía a estudiantes y docentes que publicaran sus trabajos en Med, Revisión de Artículos creaba mejores versiones de las instrucciones para los autores y se debatía entre criterios y selecciones para publicar solo lo mejor, Diseño y Diagramación utilizaba computadores y programas como si fueran publicistas para organizar los textos y los títulos para la impresión, Relaciones Públicas se movía por todos lados convenciendo a la gente de este era un proyecto en el que valía la pena creer y la División Financiera y Jurídica trataba desesperadamente de terminar de conseguir los recursos para poder funcionar.

17 de mayo de 1991. El día del lanzamiento

En el auditorio del primer piso del Hospital Militar no cabía un bata blanca más. Todos querían conocer a Med, querían saber si todo lo que se decía era cierto. Duramos casi una semana grabando un impactante audiovisual para esa tarde con una sola consigna en mente: "exceder todas las expectativas de los asistentes!"

Comenzaron los discursos, el Decano, Dr. José Antonio Rivas Rivas el Director del Hospital y nuestro primer director, Jorge Espinosa en representación de la revista... Ya llevábamos 30 minutos y todavía no teníamos ni una sola revista en la mano para el momento en el programa de la entrega oficial del primer ejemplar. Todo el mundo estaba impresionado con el nivel de expectativa que logramos, sin sospechar que 
esa expectativa era tan grande como nuestra fe en que el universo tuviera un complot para premiar todo el esfuerzo invertido.

Entonces comenzó a sonar la última frase de la presentación que decía: "Med, saldrá cada cuatro meses en una edición completamente nueva que viajará hasta todos los sitios donde se practique la medicina e ilustrará a todos aquellos que quieran ejercer su profesión de una manera actualizada y ética..."

Fue alli, solo al final, cuando uno de nosotros entro al auditorio con un paquete secreto debajo del brazo y de la manera más natural repartió los pocos ejemplares que se habían podido secar y estar listos para la ceremonia. Nadie en el auditorio podía saber que ni siquiera los que habían trabajado durante meses en Med, habían visto la impresión física del primer número de la revista y que todos cruzábamos los dedos para que el resultado final fuera más allá de lo esperado. Nadie podía saber...Hasta ahora, 25 años después.

Terminó la ceremonia. Fue un éxito rotundo. Ya no había más ilusos por un lado, ni incrédulos por el otro. Ya no había más dudas. Ahora teníamos nuestra propia revista médica. Una revista de la cual sentirnos orgullosos, y lo más importante: una revista de todos y para todos. Nos felicitaron, y abrazaron y aun no habíamos visto el resultado de nuestro trabajo.

Cuando vimos el único ejemplar que quedó, los artículos, los tipos de letra, los colores, la foto de la portada... Todo era como lo habíamos imaginado. Sentimos entonces que todos eso esfuerzos sembrados habían dado frutos. Pero también sabíamos que el trabajo no terminaba allí. Ahora teníamos que trabajar en el segundo número, que por supuesto, debería ser mejor que el anterior y sobretodo asegurarnos que Med sobreviviera al inclemente paso del tiempo...

Aunque así lo soñamos, no había forma de saber que hoy, un cuarto de siglo después, Med seguiría siendo publicada, ahora indexada en Colciencias dándole reconocimiento internacional, viajando hasta todos los sitios donde se practica la medicina e ilustrando a todos aquellos que quieran ejercer su profesión de una manera actualizada y ética.

De corazón felicitamos a la Facultad de Medicina de la Universidad Militar Nueva Granada, nuestra alma mater y a Med, por seguir en busca de la excelencia. Nuestro deseo es que esta historia de lucha contra todos los pronósticos inspire a nuevas generaciones a mantener viva a Med, el sueño de todos y para todos. 